\title{
In Focus
Spotlight on the November 25 Issue
}

\author{
Robert A. Gross, MD, PhD, FAAN \\ Editor-in-Chief, Neurology ${ }^{\circledR}$
}

\section{Posterior reversible encephalopathy syndrome with spinal cord involvement}

The authors described 8 patients with posterior reversible encephalopathy syndrome with spinal cord involvement (PRES-SCI). Patients had severe hypertension and confluent T2 hyperintensity spanning at least 4 spinal cord segments. Almost all had hypertensive retinopathy, a favorable clinical course, and resolution of the MRI lesions. PRES-SCI should be considered when evaluating myelopathy.

See p. 2002; Editorial, p. 1996

\section{Explanatory factors for the increased mortality of stroke patients with depression}

This study reports that patients on selective serotonin reuptake inhibitors have an increased poststroke mortality, but no other individual factor explains the association between depression and mortality. Poststroke depression needs clinical assessment together with effective and safe interventions in stroke survivors, particularly if they are young.

See p. 2007

From editorialists Bartoli \& Paolucci: "Special attention should be paid to antidepressant treatment, and further research is needed to analyze benefits and adverse outcomes of SSRIs in this special population."

See p. 1998

\section{Preadmission use of nonaspirin nonsteroidal anti-} inflammatory drugs and 30-day stroke mortality

Nonsteroidal anti-inflammatory drugs are widely used. In this study of first-time hospitalizations, preadmission use of cyclooxygenase (COX)-2 inhibitors was associated with increased 30-day mortality following ischemic stroke but not hemorrhagic stroke. COX-2 inhibitor use was a poor prognostic factor for ischemic stroke.

See p. 2013

Plasma $\beta$-amyloid and MRI markers of cerebral small vessel disease: Three-City Dijon Study

Plasma $\beta$-amyloid measurement and MRI examination were performed at baseline and at 4-year follow-up in 1,690 participants. Progression of white matter hyperintensity volume in dementia-free older persons was associated with levels of circulating plasma $\beta$-amyloid. These results reinforce the interrelation of vascular and neurodegenerative mechanisms in cerebral aging.

See p. 2038

\section{Functional connectivity and cognitive decline over 3 years in} Parkinson disease pt

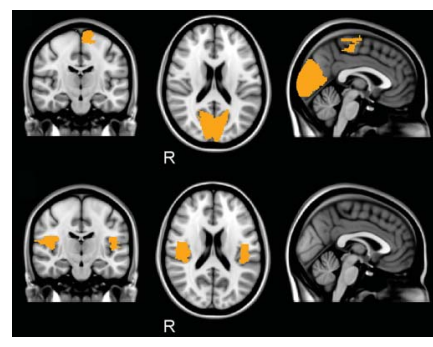

Fifty-five patients with Parkinson disease (PD) underwent resting-state fMRI, showing widespread decreases in functional connectivity (FC) compared to 15 controls. When rescanned after 3 years, patients showed further FC decreases that correlated with disease progression, especially cognitive decline. These results emphasize the pathophysiologic role of reduced FC in cognitive decline and dementia in PD.

See p. 2046; Editorial, p. 2000

\section{Objective daytime sleepiness in patients with somnambulism or sleep terrors}

Thirty drug-free adult patients with primary somnambulism or sleep terrors, and age-, sex- and body mass index-matched controls underwent a standardized clinical interview, completed questionnaires, and underwent one night of video polysomnography followed by the Multiple Sleep Latency Test. Despite increased slow-wave sleep fragmentation in patients with somnambulism or sleep terrors, no association was found with the level of daytime sleepiness.

See p. 2070

Effects of a HLA-B*15:02 screening policy on antiepileptic drug use and severe skin reactions

This study used whole-population, real-world data to track changes in antiepileptic drug prescription practice and the incidence of severe cutaneous adverse drug reactions. Following the implementation of universal HLA-B*15:02 screening prior to carbamazepine use, there were fewer carbamazepine prescriptions and related adverse skin reactions were eliminated, although the overall rate of skin reactions was unchanged because other drugs that induced such reactions were used. These findings emphasize the challenges in implementing pharmacogenetic screening.

See p. 2077

NB: "Dementia: Challenges of practice in Pakistan," see p. 2091. To check out other Global Perspectives submissions, point your browser to Neurology.org. 


\title{
Neurology
}

\author{
Spotlight on the November 25 Issue \\ Robert A. Gross \\ Neurology 2014;83;1995 \\ DOI 10.1212/WNL.0000000000001039
}

This information is current as of November 24, 2014

\section{Updated Information \&}

Services

Permissions \& Licensing

Reprints including high resolution figures, can be found at: http://n.neurology.org/content/83/22/1995.full

Information about reproducing this article in parts (figures,tables) or in its entirety can be found online at:

http://www.neurology.org/about/about_the_journal\#permissions

Information about ordering reprints can be found online:

http://n.neurology.org/subscribers/advertise

Neurology ${ }^{\circledR}$ is the official journal of the American Academy of Neurology. Published continuously since 1951, it is now a weekly with 48 issues per year. Copyright @ 2014 American Academy of Neurology. All rights reserved. Print ISSN: 0028-3878. Online ISSN: 1526-632X.

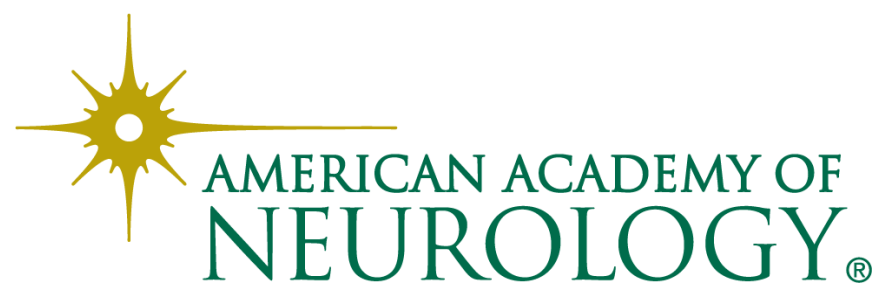

